\title{
Técnicas de geoinformação para estimativa do balanço hídrico em eucalipto
}

\author{
Alexandro Gomes Facco(1), Aristides Ribeiro(2), Fernando Falco Pruski(2), Welliam Chaves Monteiro(2), \\ Fernando Palha Leite ${ }^{(3)}$, Ricardo Guimarães Andrade ${ }^{(4)}$ e Sady Júnior Martins da Costa de Menezes(5)
}

\begin{abstract}
(1)Universidade Federal do Espírito Santo, Centro Universitário Norte do Espírito Santo, Departamento de Ciências Agrárias e Biológicas, CEP 29932-540 São Mateus, ES. E-mail: agfacco@ceunes.ufes.br (2)Universidade Federal de Viçosa, Departamento de Engenharia Agrícola, CEP 36570-000 Viçosa, MG. E-mail: ribeiro@ufv.br, ffpruski@ufv.br, wcms00@gmail.com ${ }^{(3)}$ Celulose Nipo-Brasileira, Caixa Postal 100, CEP 35196-97 Belo Oriente, MG. E-mail: fernando.leite@cenibra.com.br (4)Embrapa Monitoramento por Satélite, Avenida Soldado Passarinho, № 303, Fazenda Chapadão, CEP 13070-115 Campinas, SP. E-mail: ricardo@cnpm.embrapa.br (5)Universidade Federal Rural do Rio de Janeiro, Instituto Três Rios, Avenida Prefeito Alberto da Silva Lavinas, no 1.847, Centro, CEP 25802-100 Três Rios, RJ. E-mail: sadymenezes@yahoo.com.br
\end{abstract}

Resumo - O objetivo deste trabalho foi avaliar a influência da topografia no balanço de radiação e na disponibilidade hídrica em microbacia hidrográfica com plantio de eucalipto, bem como verificar os efeitos dos plantios de eucalipto na regularização do escoamento da água. Foram monitorados os componentes do balanço hídrico em uma microbacia hidrográfica localizada na região Leste do Estado de Minas Gerais. Os componentes do balanço hídrico foram computados pontual e espacialmente, em escala horária, para a camada útil do solo. Os resultados foram comparados com os valores medidos a partir da lâmina escoada pelo curso d'água. Nos meses em que houve disponibilidade de água no solo, os valores médios da transpiração real, estimada a partir do método espacial, foram maiores que os estimados pelo método pontual. A estimativa do balanço hídrico é mais eficiente quando considera os efeitos do relevo. As florestas de eucalipto regulam o escoamento de água em microbacias hidrográficas.

Termos para indexação: armazenamento de água no solo, microbacia experimental, regulação do escoamento, relevo, sistema de informação geográfica.

\section{Geoinformation techniques to estimate water balance in eucalyptus}

\begin{abstract}
The objective of this work was to evaluate the influence of topography on radiation balance and water availability in micro watersheds planted with eucalyptus, and to verify the effects of eucalyptus plantations in regulating water flow. Water balance components were monitored in a micro watershed located in the Eastern region of the state of Minas Gerais, Brazil. Water balance components were computed punctually and spatially, in hourly time scale, for the useful layer of soil. The results were compared with the values measured from the water depth drained by the watercourse. In months with soil water availability, the average values of real transpiration estimated by the spatial method were higher than those estimated by the punctual method. Water balance estimation is more efficient when it considers the relief effects. Eucalyptus forests regulate water flow in micro watersheds.
\end{abstract}

Index terms: soil water storage, experimental micro watershed, water flow regulation, relief, geographic information system.

\section{Introdução}

As florestas desempenham importante papel na captação e na distribuição da água de chuva nas bacias hidrográficas, no processo de suprimento de água para a recarga dos aquíferos e na regulação do escoamento de água nas microbacias. O consumo de água por elas pode ser influenciado por fatores climáticos, edáficos e fisiológicos, como: demanda evaporativa do ar; quantidade de água no solo; e condutância da copa, controlada pela condutância estomática e área foliar.

Os efeitos da silvicultura sobre os recursos hídricos não são simples de serem quantificados. Cossalter \& Pye-Smith (2003), Svetlitchnyi et al. (2003) e Lin et al. (2006) analisaram microbacias experimentais e avaliaram, de modo eficiente, a produção e a qualidade da água dos cursos d'água. No entanto, são raros os trabalhos que levam em consideração a influência

Pesq. agropec. bras., Brasília, v.47, n.9, p.1243-1250, set. 2012 
da topografia no fluxo da água e, principalmente, no balanço energético, ao se determinar os componentes do balanço hídrico em microbacias hidrográficas (Ribeiro et al., 2005; Neves et al., 2007; Facco et al., 2009; Elsebaii et al., 2010; Souza et al., 2010). Alguns estudos têm investigado os efeitos de florestas plantadas sobre a quantidade e qualidade da água, e provido informações sobre modelagens dos componentes do balanço hídrico para eucalipto (Hubbard et al., 2004, 2009; Carneiro et al., 2008; Gartner et al., 2009).

O desenvolvimento de sistemas de informações geográficas aplicados à hidrologia, associado ao aumento do poder computacional, tem possibilitado estimar espacialmente os componentes do balanço hídrico e simular suas interações com a topografia.

O objetivo deste trabalho foi avaliar a influência da topografia no balanço de radiação e na disponibilidade hídrica em microbacia hidrográfica com plantio de eucalipto, bem como verificar os efeitos dos plantios de eucalipto na regularização do escoamento da água em microbacia experimental.

\section{Material e Métodos}

O estudo foi conduzido em microbacia hidrográfica localizada no Município de Antônio Dias, região do Vale do Rio Doce, MG $\left(19^{\circ} 28^{\prime} \mathrm{S}\right.$ e $\left.42^{\circ} 49^{\prime} \mathrm{W}\right)$. Essa área pertence à empresa Celulose Nipo-Brasileira S.A (Cenibra). A microbacia apresenta relevo de forte-ondulado a montanhoso (De Biase, 1993). O solo predominante é o Cambissolo latossólico, com capacidade de campo de $0,35 \mathrm{~m}^{3} \mathrm{~m}^{-3}$ e ponto de murcha permanente de $0,18 \mathrm{~m}^{3} \mathrm{~m}^{-3}$. A cobertura do solo era composta, basicamente, por florestas de Eucalyptus grandis, plantadas em 2003, e por floresta com espécies nativas.

O espaçamento dos plantios de eucalipto era em torno de $3 \times 3,33 \mathrm{~m}$. As margens do curso d'água eram ocupadas por florestas com espécies nativas e capoeira. O solo era recoberto por espessa serrapilheira, e as margens do córrego encontravam-se bem protegidas, sem sinais de erosão. A calibração e a validação do modelo de armazenamento de água no solo foram feitas com dados de precipitação $(\mathrm{P})$ e de vazão do córrego, registrados em intervalos de $5 \mathrm{~min}$. Foram utilizados dados meteorológicos horários de 2005 e 2006, provenientes de estação automática instalada em torre de $30 \mathrm{~m}$ de altura, localizada na microbacia estudada.
Nessa torre micrometeorológica, a umidade relativa do ar (UR), a temperatura do ar (T) e a velocidade do vento $(\mathrm{u})$ foram monitoradas em quatro níveis: 1, 2, 4 e $16 \mathrm{~m}$ a partir das copas das árvores. Essa distribuição foi utilizada para a determinação do perfil dos fluxos ascendentes que passam pelas árvores, com o intuito de melhorar a estimativa da transpiração das plantas e da resistência aerodinâmica, conforme Rodrigues \& Pita (2003).

O modelo de armazenamento de água no solo foi implementado no programa ArcGIS 9.3.1 (Imagem Geosistemas e Comércio Ltda., São José dos Campos, $\mathrm{SP}$ ), com uso da linguagem de programação Visual Basic. O modelo de armazenamento de água teve como base um modelo digital do terreno, hidrologicamente consistente, com resolução espacial de $4 \mathrm{~m}$. A simulação foi horária.Quandoocorreprecipitação, háinterceptação pela cobertura vegetal (ICV). Se a intensidade de precipitação (Ip) for maior que a taxa de infiltração (TI), parte da precipitação escoará superficialmente (ES); caso contrário, toda a precipitação infiltrará no solo. Se a precipitação continuar, a água será armazenada na camada do solo que contém as raízes, comumente denominada de camada útil do solo, até a umidade atingir capacidade máxima de água disponível (CAD). Quando esta umidade for superada, o excedente será perdido por percolação profunda (Pp) (Figura $1 \mathrm{~A})$.

Após ajustar a irradiação solar global (Rgs) e a temperatura do ar $\left(\mathrm{T}_{\text {ajust }}\right)$, tendo-se considerando a topografia da microbacia, associou-se a umidade relativa (UR), para calcular o deficit de pressão de vapor (DPV), e, em seguida, estimou-se o índice de área foliar (IAF) e a resistência do dossel (rs) (Figura $1 \mathrm{~B}$ ). O fluxo de calor no solo $(\mathrm{G})$ foi estimado tendo-se considerado a hora do dia. Durante o período diurno, o fluxo de calor foi calculado em função da $\mathrm{Rg}$ e, no período noturno, em função do saldo de radiação $(\mathrm{Rn})$. A resistência aerodinâmica $(\mathrm{Ra})$ foi estimada com ajuste da velocidade do vento a $30 \mathrm{~m}\left(\mathrm{U}_{30}\right)$, para a altura da planta (Uz), calculada em função da idade. O ajuste da transpiração real (TRr) considera a ocorrência ou não de precipitação.

Os componentes do balanço hídrico foram estimados com base em modelo digital do terreno (MDT), tipo de solo, cobertura vegetal e dados meteorológicos em escala horária. A partir do MDT, determinaram-se altitudes, sombreamentos, inclinações e orientações das encostas para cada pixel. Considerou-se, para 
o ajustamento da irradiação solar global, o efeito do sombreamento, da inclinação e da orientação das rampas. O sombreamento foi determinado em função

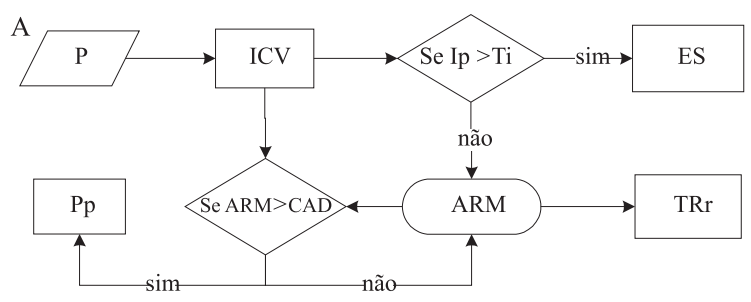

B

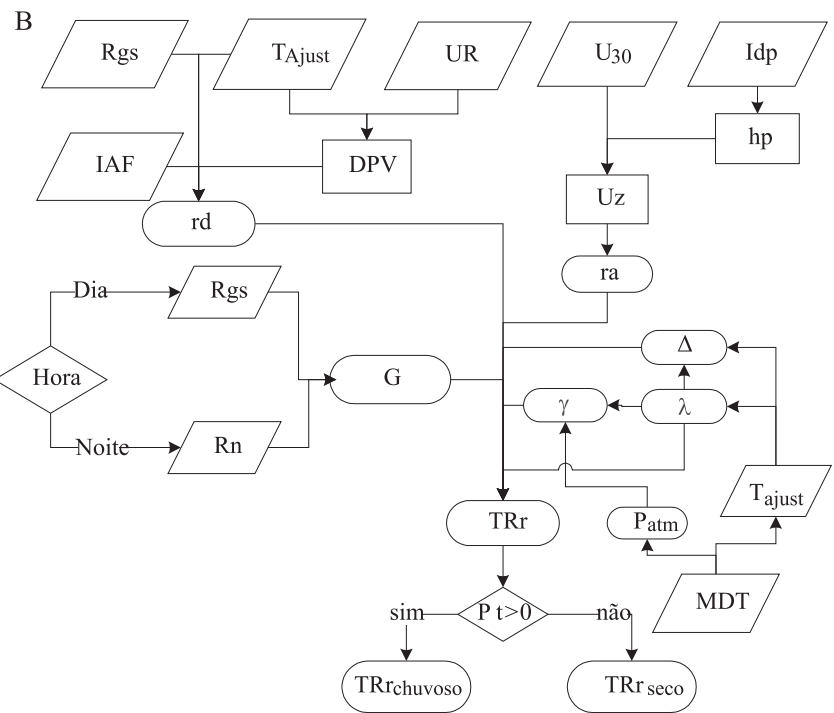

Figura 1. Submodelos de determinação da A, transpiração real em que $\mathrm{Uz}$, velocidade do vento a altura da planta $\left(\mathrm{m} \mathrm{s}^{-1}\right)$; ARM, armazenamento de água na camada útil do solo $(\mathrm{mm})$; CAD, capacidade máxima de água disponível $(\mathrm{mm})$; ES, escoamento superficial (mm); ICV, interceptação pela cobertura vegetal $(\mathrm{mm})$; Ip, intensidade de precipitação $\left(\mathrm{mm} \mathrm{h}^{-1}\right)$; P, precipitação $(\mathrm{mm})$; Pp, perda por percolação profunda $(\mathrm{mm})$; e Ti, taxa de infiltração $\left(\mathrm{mm} \mathrm{h}^{-1}\right)$; e do B, armazenamento da água no solo, em que $\gamma$, coeficiente psicrométrico $\left(\mathrm{kPa}^{\circ} \mathrm{C}^{-1}\right) ; \lambda$, calor latente de evaporação (MJ m kg$\left.{ }^{-1}\right) ; \Delta$, declividade da curva de pressão de vapor $\left(\mathrm{kPa}^{\circ} \mathrm{C}^{-1}\right)$; DPV, deficit de pressão de vapor $(\mathrm{kPa}) ; \mathrm{G}$, fluxo de calor no solo $\left(\mathrm{MJ} \mathrm{m}^{-2} \mathrm{~h}^{-1}\right)$; IAF, índice de área foliar $\left(\mathrm{m} \mathrm{m}^{-1}\right)$, Idp, idade da planta (anos); hp, altura da planta (m); MDT, modelo digital do terreno; Patm, pressão atmosférica $(\mathrm{kPa})$; Ra, resistência aerodinâmica $\left(\mathrm{s} \mathrm{m}^{-1}\right)$; Rd, resistência do dossel da planta $\left(\mathrm{s} \mathrm{m}^{-1}\right)$; Rgs, irradiação solar global ajustada ( $\mathrm{MJ} \mathrm{m}^{-2} \mathrm{~h}^{-1}$ ); Rn, saldo de radiação $\left(\mathrm{MJ} \mathrm{m}^{-2} \mathrm{~h}^{-1}\right)$; $\mathrm{T}_{\text {ajust, }}$ temperatura do ar ajustada $\left({ }^{\circ} \mathrm{C}\right)$; $\mathrm{TRr}$, transpiração real $\left(\mathrm{mm} \mathrm{h}^{-1}\right)$; $\mathrm{TRr}$ chuvoso, transpiração real ajustada para período com chuva $\left(\mathrm{mm} \mathrm{h}^{-1}\right)$; TRr seco, transpiração real para período sem chuva $\left(\mathrm{mm} \mathrm{h}^{-1}\right)$; U30, velocidade do vento

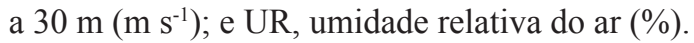

da topografia da bacia e da posição aparente do sol. Para as áreas sombreadas, considerou-se apenas a componente difusa da Rg, e, nas demais áreas, ajustouse a componente direta da $\mathrm{Rg}$, em função da inclinação e da orientação das rampas e da posição aparente do sol. A irradiação solar global ajustada (Rgs) foi obtida pela soma da radiação solar direta e difusa. Ao se subtrair a irradiação refletida da Rgs, obteve-se o balanço de ondas curtas (BOC). Na estimativa do balaço de ondas longas (BOL), foram considerados os ajustes da temperatura do ar em função da topografia (Figura 2).

Os cálculos do balanço hídrico foram iniciados a partir de janeiro de 2005, quando a precipitação acumulada foi suficiente para atingir a capacidade máxima de

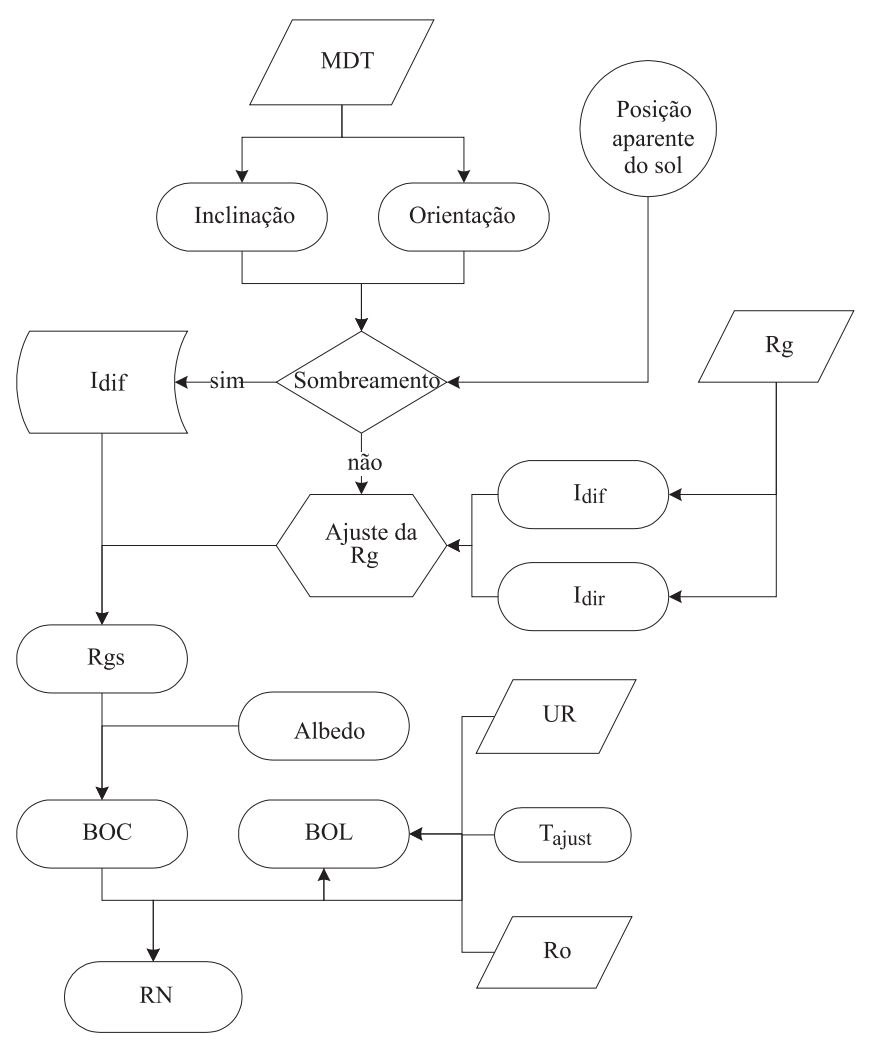

Figura 2. Fluxograma das etapas envolvidas no processo de obtenção do saldo de radiação, em que BOC, balanço de ondas curtas $\left(\mathrm{MJ} \mathrm{m}^{-2} \mathrm{~h}^{-1}\right)$; BOL, balanço de ondas longas $\left(\mathrm{MJ} \mathrm{m} \mathrm{m}^{-2} \mathrm{~h}^{-1}\right) ; \mathrm{I}_{\text {dir }}$, irradiância solar difusa $\left(\mathrm{MJ} \mathrm{m} \mathrm{m}^{-2} \mathrm{~h}^{-1}\right)$; $\mathrm{I}_{\text {dif }}$, irradiância solar difusa $\left(\mathrm{MJ} \mathrm{m}^{-2} \mathrm{~h}^{-1}\right)$; Ro, irradiação solar global no topo da atmosfera $\left(\mathrm{MJ} \mathrm{m}^{-2} \mathrm{~h}^{-1}\right)$; Rg, irradiação solar global (MJ m $\left.{ }^{-2} \mathrm{~h}^{-1}\right)$; Rgs, irradiação solar global ajustada $\left(\mathrm{MJ} \mathrm{m} \mathrm{m}^{-2} \mathrm{~h}^{-1}\right) ; \mathrm{RN}$, saldo de radiação solar $\left(\mathrm{MJ} \mathrm{m} \mathrm{m}^{-2} \mathrm{~h}^{-1}\right)$; $\mathrm{T}_{\text {ajust }}$, temperatura do ar ajustada $\left({ }^{\circ} \mathrm{C}\right)$; e UR, umidade relativa do $\operatorname{ar}(\%)$. 
água armazenada no solo (CAD). O balanço hídrico foi calculado para a camada de solo que contém as raízes, a qual varia em função da idade das plantas. Neste volume de controle, a variação do armazenamento de água no solo foi dada pela contabilização da entrada e da saída de água: $\mathrm{ARM}_{\mathrm{i}}=\mathrm{ARM}_{\mathrm{i}-1}+\mathrm{P}_{\mathrm{i}}-\mathrm{ICV}_{\mathrm{i}}-\mathrm{TR}_{\mathrm{i}}-$ $\mathrm{E}_{\mathrm{h}}$, em que $\mathrm{ARM}_{\mathrm{i}}$ é o armazenamento de água no dia i (mm); $\mathrm{ARM}_{\mathrm{i}-1}$ é o armazenamento de água no dia anterior $(\mathrm{mm})$; $\mathrm{P}_{\mathrm{i}}$ é a precipitação pluvial total no dia i (mm); $\mathrm{ICV}_{\mathrm{i}}$ é o total interceptado de água da chuva pelo dossel e pela serrapilheira no dia $\mathrm{i}(\mathrm{mm}) ; \mathrm{TR}_{\mathrm{i}}$ é a transpiração no dia i (mm); e $E_{h}$ é o excesso hídrico (mm).

Para o cálculo da CAD, foi utilizado o modelo matemático desenvolvido por Calegario et al. (2005), ajustado à base de dados amostrais coletada para determinar a profundidade do sistema radicular (PSR) em plantios de eucalipto, na região de Aracruz, ES, com unidade em centímetros, PSR $=287,31 \times\left(1-\mathrm{e}^{-0,19483 \times \text { IDP }}\right)^{1,0219}$, em que: Idp é a idade da planta (anos).

Em razão da dificuldade de implementação computacional, a intercepção pela cobertura vegetal (ICV), que inclui interceptações pelo dossel, pelo tronco e pela serrapilheira, foi calculada apenas sem considerar o efeito da topografia. Para tanto, foi aplicado o modelo proposto por Ribeiro et al. (2005).

Para a estimativa da transpiração potencial $\left(\mathrm{TR}_{\mathrm{p}}\right)$, foi utilizada a equação de Penman-Monteith (1965). A resistência aerodinâmica (ra) foi estimada com uso da equação apresentada por Allen et al. (1998), calibrada a partir dos dados de velocidade do vento, coletados na torre micrometeorológica. A estimativa da resistência estomática (rs) foi realizada por meio do modelo proposto por Carneiro et al. (2008), rs $=412,93 \times\left(\mathrm{DPV} \times \mathrm{T} \times \mathrm{Rgs}^{-1}\right)^{0,5741}$, em que: DPV é o deficit de pressão de vapor $(\mathrm{kPa})$; $\mathrm{T}$ é a temperatura do ar; e Rgs é a irradiação solar global ajustada ( $\mathrm{MJ} \mathrm{m}^{-1}$ por dia).

A transpiração potencial foi multiplicada pelo coeficiente de umidade do solo $\left(\mathrm{K}_{\mathrm{s}}\right)$, para obtenção da transpiração real.

Foram utilizados dados dos perfis de vento, temperatura e umidade relativa do ar para ajustar o modelo de TRr para os períodos com e sem ocorrência de chuvas. Para esse ajuste, aplicou-se o método da razão de Bowen (Twine et al., 2000).
A altura média das árvores (hp) e o índice de área foliar (IAF) foram estimados com base na idade da planta (Idp), conforme proposto por Ribeiro et al. (2005): $\mathrm{h}_{\mathrm{p}}=-0,2085+7,2478 \mathrm{I}_{\mathrm{dp}}-0,5306 \mathrm{I}_{\mathrm{dp}}{ }^{2}$; $\mathrm{IAF}=-0,56 \mathrm{I}_{\mathrm{dp}}+4,9033$.

A média diária da temperatura do ar foi ajustada em função da altitude de cada pixel, por meio do MDT. Para isso, aplicou-se variação de $-0,7^{\circ} \mathrm{C}$ na temperatura do ar, a cada $100 \mathrm{~m}$ de aumento na altitude da célula em relação à da estação meteorológica (Vianello et al., 2002).

O saldo de radiação foi calculado de acordo com Facco (2009).

Considerou-se, como excesso hídrico (Eh), a água perdida tanto por escoamento superficial como por percolação profunda: $\mathrm{E}_{\mathrm{h}}=\left(\mathrm{ARM}_{\mathrm{i}-1}+\mathrm{P}_{\mathrm{i}}-\mathrm{ICV}_{\mathrm{i}}-\mathrm{TR}_{\mathrm{i}}\right)-\mathrm{CAD}$, dado que se $\mathrm{E}_{\mathrm{h}}<0$, então $\mathrm{E}_{\mathrm{h}}=0$.

Utilizou-se o teste t, a $5 \%$ de probabilidade, para comparar o método pontual com o espacial.

\section{Resultados e Discussão}

Os totais de precipitação de 2005 e 2006 foram de 1.545 e $1.387 \mathrm{~mm}$, respectivamente. Já o total anual médio, com base na série histórica de 23 anos, da estação meteorológica da Cenibra, localizada a $15 \mathrm{~km}$ da área experimental, foi de $1.281 \mathrm{~mm}$. Assim como o total de precipitação, a radiação solar, a temperatura, a umidade relativa do ar e a velocidade do vento também não diferiram significativamente da série histórica.

Com base nos dados meteorológicos coletados na torre da bacia experimental, foi possível ajustar o modelo de transpiração proposto por Carneiro et al. (2008) com o método da razão de Bowen (Figura 3). No ajuste, considerou-se a individualização da transpiração em cenários com e sem a ocorrência de chuvas. Verificou-se que o modelo de Carneiro et al. (2008) superestimou a transpiração em 59,12\%, com chuvas, e $35,06 \%$, sem.

O sol fica posicionado ao norte da microbacia a maior parte do ano. Essa posição aparente do sol faz com que as encostas voltadas para o sul recebam menos irradiação solar durante o ano. Essa atenuação é intensificada nos meses de inverno, quando se observaram variações de até $50 \%$ entre a transpiração do eucalipto nas encostas voltadas ao sul e ao norte. Resultados semelhantes foram obtidos por Turco \& Rizzatti (2006) e Facco et al. (2009). 
Ao se comparar as médias da variação espacial da transpiração real obtidas pelo método espacial $\left(\mathrm{TRr}_{\text {espacial }}\right)$ com as obtidas pelo método pontual ( $\left.\mathrm{TRr}_{\text {pontual }}\right)$, observou-se que, nos dois anos analisados, nos meses que apresentaram armazenamento de água no solo (ARM) disponível para o eucalipto, a $\mathrm{TRr}_{\text {espacial }}$ ficou, em média, 25\% acima da $\mathrm{TRr}_{\text {pontual }}$. Já nos meses em que o ARM era menor, a $\mathrm{TRr}_{\text {espacial }}$ ficou, em média, 14\% abaixo da $\mathrm{TRr}_{\text {pontual }}$ (Figura $4 \mathrm{~A}$ e B). Em ambos os períodos, as médias de $\mathrm{TRr}_{\text {espacial }}$ e da $\mathrm{TRr}_{\text {pontual }}$ foram significativamente diferentes. Esses resultados são indicativos de que, quando há disponibilidade de água no solo para a planta, as características do relevo exercem influência na transpiração do eucalipto.

De forma geral, para janeiro a maio de 2005 e 2006, a média da $\mathrm{TRr}_{\text {pontual }}$ diária foi de $2,11 \mathrm{~mm}$ e a da
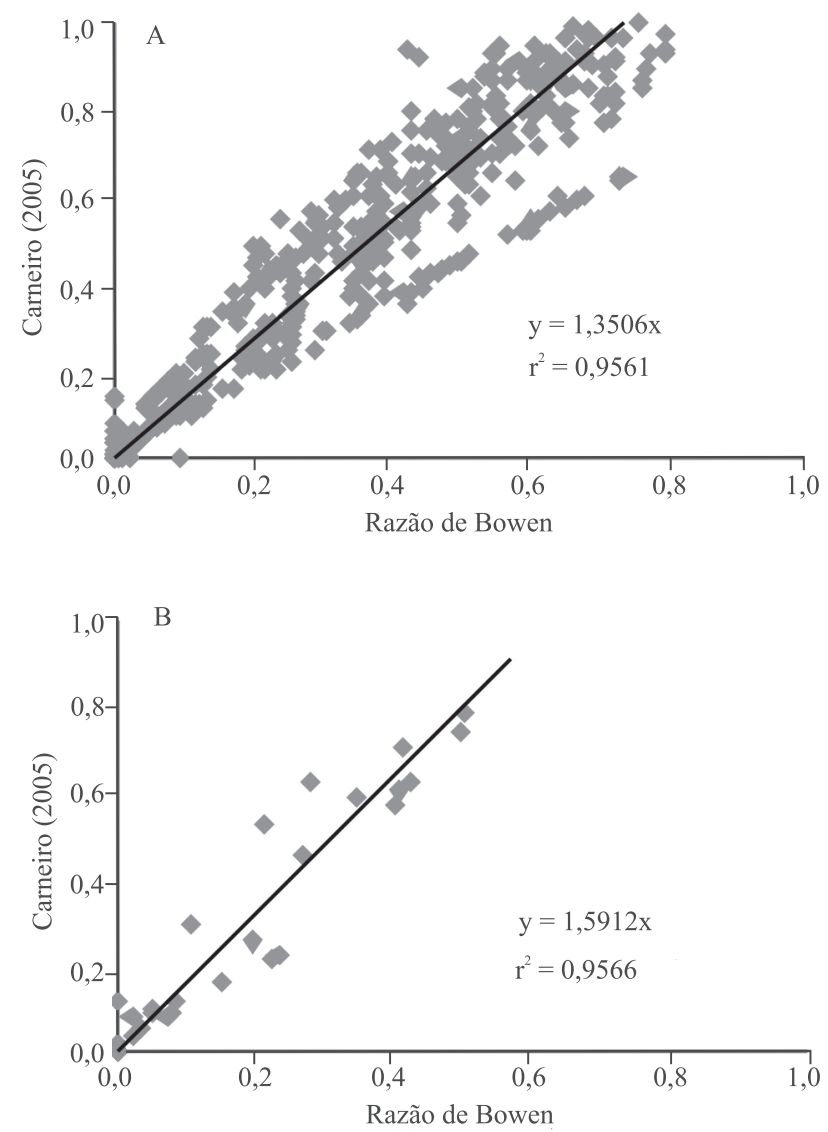

Figura 3. Ajuste do modelo de regressão linear simples para transpiração, proposto por Carneiro et al (2008), para o período com (A) e sem chuva (B).
$\mathrm{TRr}_{\text {espacial }}$ foi de $2,95 \mathrm{~mm}$. De agosto a dezembro, esses valores foram de 2,17 e 1,70 mm, respectivamente.

Em 2005, a média da transpiração real na microbacia foi de $746 \pm 28,01 \mathrm{~mm}$ (equivalente a $2,04 \mathrm{~mm}$ por dia). As rampas com encostas voltadas para sul e leste apresentaram os menores valores de transpiração real (Figura 5), o que pode ser atribuído à posição do sol ao norte da microbacia, na maior parte do ano. Além disso, a inclinação das rampas, no lado oeste da bacia, pode ter influenciado a diminuição da incidência de radiação solar global direta. Essa variação foi mais bem observada nas estimativas realizadas para 2006. Percebeu-se, nitidamente, redução da TRr nas encostas voltadas para o sul. Nesse ano, o valor médio do total transpirado foi de $859 \pm 30,36 \mathrm{~mm}$, equivalente

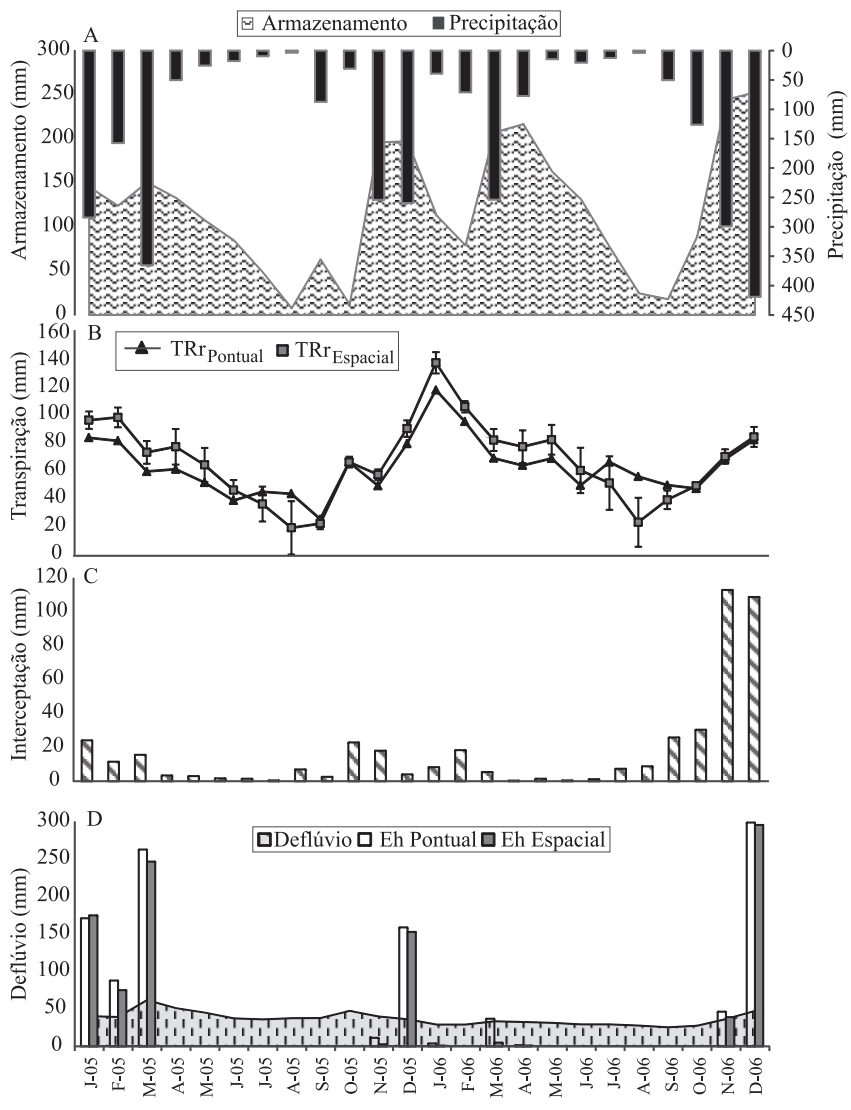

Figura 4. Variação temporal do total mensal de: A, precipitação e armazenamento de água no solo; B, transpiração pontual ( $\left.\mathrm{TRr}_{\text {pontual }}\right)$ e transpiração espacial $\left(\mathrm{TRr}_{\text {espacial }}\right)$; C, interceptação pela cobertura vegetal; e D, deflúvio escoado no exutório da microbacia e totais mensais do excesso hídrico, estimado a partir dos métodos pontual e espacial, dado em mm, para área de abrangência da microbacia. 
a 2,35 $\mathrm{mm}$ por dia. O aumento da TRr, em 2006, foi explicado pela ocorrência de chuvas bem abaixo da média em janeiro e fevereiro, o que influenciou a irradiação solar pela pouca nebulosidade.

Essas taxas de transpiração foram menores que as obtidas por Gentil (2010), para plantios de eucalipto irrigado e não irrigado, com quatro anos de idade, cuja média diária de transpiração foi da ordem de $6,8 \mathrm{~mm}$ entre agosto e dezembro. Carneiro et al. (2008) encontraram transpiração de 8,6 e $6,17 \mathrm{~mm}$ por dia para plantios jovens de eucaliptos submetidos a tratamentos com e sem irrigação, respectivamente. Soares \& Almeida (2001) relataram, para E. grandis, valores de transpiração entre 1,1 e 5,8 $\mathrm{mm}$ por dia.

As maiores interceptações da precipitação pela cobertura vegetal ocorreram de abril a agosto (Figura 4 C). Em geral, as precipitações que ocorreram nesses meses foram de baixas intensidades, o que favoreceu sua interceptação. A interceptação média, nos dois anos, foi de $7,7 \%$ do total precipitado. Em 2005, foi de $113 \mathrm{~mm}$, o que representou 7,31\% do total precipitado no ano. Em 2006, ela foi de $109 \mathrm{~mm}$ e representou $8,07 \%$ da precipitação. Baumhardt (2010) encontrou interceptação de $14,6 \%$, em florestas adultas de E. urograndis, no Rio Grande do Sul.

Em 2005, ocorreram excessos hídricos em janeiro, fevereiro, março, novembro e dezembro, que perfizeram um total médio de $693 \mathrm{~mm}$, para as estimativas obtidas a partir do método pontual, e de $653 \pm 24,59 \mathrm{~mm}$ a partir do método espacial (Figura 4 D). Já em 2006, ocorreram excessos em janeiro, março, abril, novembro e dezembro, o que totalizou 388 e $340 \pm 36,16 \mathrm{~mm}$, estimados a partir do método pontual e espacial, respectivamente. Esses resultados indicam que o plantio de eucalipto é bom regulador do escoamento da água e favorece a permanência desta na microbacia. Apesar da diferença entre os totais precipitados nos períodos de estiagens e de chuvas, em termos mensais, o deflúvio foi pouco influenciado.

Ao se assumir que a precipitação e a interceptação são iguais nos três métodos de determinação do balanço hídrico, observou-se que o método de estimativa

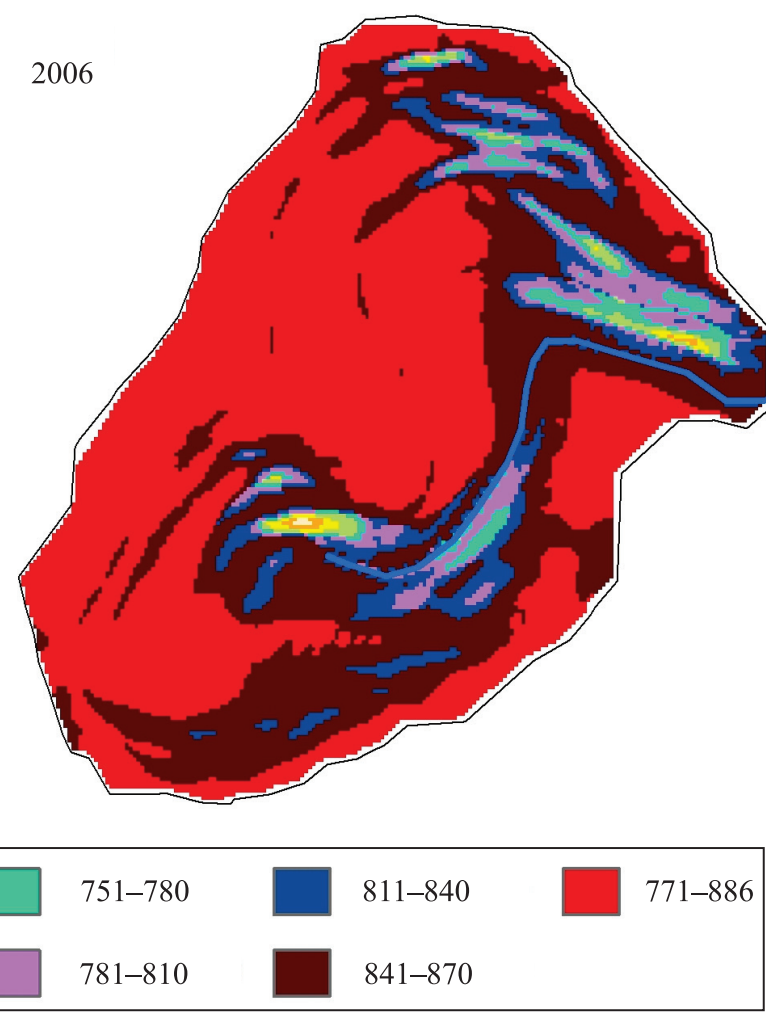

Figura 5. Variação espacial e temporal do total anual de transpiração real (mm) para 2005 e 2006. 
Tabela 1. Comparação entre os métodos estimados e medidos, quanto a precipitação, transpiração real, interceptação pela cobertura vegetal, excesso hídrico e armazenamento de água no solo.

\begin{tabular}{lccccccc}
\hline $\begin{array}{l}\text { Componentes } \\
\text { do balanço } \\
\text { hídrico }\end{array}$ & $\begin{array}{c}\text { Pontual } \\
(\mathrm{mm})\end{array}$ & $\begin{array}{c}\text { Espacial } \\
(\mathrm{mm})\end{array}$ & $\begin{array}{c}\text { Medido } \\
(\mathrm{mm})\end{array}$ & & $\begin{array}{c}\text { Pontual } \\
(\mathrm{mm})\end{array}$ & $\begin{array}{c}\text { Espacial Medido } \\
(\mathrm{mm})\end{array}$ & $(\mathrm{mm})$ \\
\hline Precipitação & 1.545 & 1.545 & 1.545 & & 1.349 & 1.349 & 1.349 \\
Transpiração real & 682 & 746 & 925 & & 714 & 859 & 893 \\
Interceptação & 113 & 113 & 113 & & 109 & 109 & 109 \\
Excesso hídrico & 693 & 653 & 508 & & 384 & 340 & 347 \\
Armazenamento & 58 & 33 & 0 & & 142 & 41 & 0 \\
\hline
\end{tabular}

pontual da transpiração real foi o que mais diferiu da transpiração medida (Tabela 1).

Para 2005, a $\mathrm{TRr}_{\text {pontual }}$ foi $35,5 \%$ menor que a medida, e, em 2006, foi $25 \%$ menor. Já a $\mathrm{TRr}_{\text {espacial, }}$ foi 23,9 e 3,9\% menor que a medida em 2005 e 2006, respectivamente. Essas diferenças entre a $\mathrm{TRr}_{\text {espacial }} \mathrm{e}$ a medida são devidas ao fato de toda a precipitação, na medição, ter sido convertida em transpiração real, interceptação pela cobertura vegetal e excesso hídrico, não tendo restado nenhum aporte para o armazenamento de água no solo. No entanto, no presente trabalho, durante todo o monitoramento da vazão do curso d'água, houve descarga pelo exutório da microbacia. Assim, presume-se que a transpiração real medida foi menor, embora não tenha sido possível quantificá-la, uma vez que o período de dois anos de monitoramento é muito curto. Para as estimativas realizadas em 2005, verificou-se que $33 \%$ da precipitação foi convertida em deflúvio. Em 2006, o deflúvio foi de 25,7\%. Contudo, menor conversão (14,3\%) foi observada por Baumhardt (2010).

De modo geral, apesar do curto período de coleta de dados para a avaliação das metodologias, os resultados obtidos revelam a importância da aplicação de tecnologias da geoinformação para estimativa do balanço hídrico real, em áreas de relevo montanhoso.

\section{Conclusões}

1. O método de estimativa do balanço hídrico é mais eficiente quando considera os efeitos do relevo.

2. As características do relevo influenciam de forma considerável as taxas de transpiração, quando há disponibilidade de água no solo para a planta.

3. Florestas de eucalipto regulam o escoamento da água e a retêm nas microbacias hidrográficas.

\section{Referências}

ALlEN, R.G.; PEREIRA, L.S.; RAES, D.; SMITH, M. Crop Evapotranspiration: guidelines for computing crop requirements. Rome: FAO, 1998. 300p.

BAUMHARDT, E. Balanço hídrico de microbacia com eucalipto e pastagem nativa na região da campanha do RS. 2010. 138p. Dissertação (Mestrado) - Universidade Federal de Santa Maria, Santa Maria.

CALEGARIO, N.; DANIELS, R.F.; SOUZA, A.L.; MAESTRI, R. Estimativa do crescimento de povoamentos de Eucalyptus baseada em modelos lineares em multiníveis de efeito misto. Revista Árvore, v.29, p.251-264, 2005.

CARNEIRO, R.L. de C.; RIBEIRO, A.; HUAMAN, C.A.M. y; LEITE, F.P.; SEDIYAMA, G.C.; NEVES, J.C.L. Consumo de água em plantios de eucalipto: parte 2 modelagem da resistência estomática e estimativa da transpiração em tratamentos irrigados e não-irrigados. Revista Árvore, v.32, p.11-18, 2008.

COSSALTER, C.; PYE-SMITH, C. Fast-wood forestry: myths and realities. Bogor: CIFOR, 2003. 54p. (Forest perspectives, 1).

DE BIASE, M. A carta clinográfica: os métodos de representação e sua confecção. Revista de Geografia, v.6, p.45-60, 1993.

EL-SEBAII, A.A.; AL-HAZMI, F.S.; AL-GHAMDI, A.A.; YAGHMOUR, S.J. Global, direct and diffuse solar radiation on horizontal and tilted surfaces in Jeddah, Saudi Arabia. Applied Energy, v.87, p.568-576, 2010.

FACCO, A.G.; RIBEIRO, A.; SEDIYAMA, G.C.; LEITE, F.P.; BARROS, N.F. de. Saldo de radiação em plantios de eucalipto em áreas de relevo ondulado. Revista Árvore, v.33, p.471-480, 2009.

GARTNER, K.; NADEZHDINA, N.; ENGLISCH, M.; C`ERMAK, J.; LEITGEB, E. Sap flow of birch and Norway spruce during the European heat and drought in summer 2003. Forest Ecology and Management, v.258, p.590-599, 2009.

GENTIL, M.S. Transpiração e eficiência do uso da água em árvores clonais de Eucalyptus aos 4 anos em áreas com e sem irrigação em Eunápolis, Bahia. 2010. 71p. Dissertação (Mestrado) - Escola Superior de Agricultura Luiz de Queiroz, Piracicaba.

HUBBARD, R.M.; RYAN, M.G.; GIARDINA, C.P.; BARNARD, $H$. The effect of fertilization on sap flux and canopy conductance in a Eucalyptus saligna experimental forest. Global Change Biology, v.10, p.427-436, 2004.

HUBBARD, R.M.; STAPE, J.L.; RYAN, M.; ALMEIDA, A.C.; DELGADO ROJAS, J.S.D. Effects of irrigation on water use and water use efficiency in two fast growing Eucalyptus plantations. Forest Ecology and Management, v.259, p.1714-1721, 2009.

LIN, H.S.; KOGELMANN, W.; WALKER, C.; BRUNS, M.A. Soil moisture patterns in a forested catchment: a hydropedological perspective. Geoderma, v.131, p.345-368, 2006.

NEVES, B.V.B.; VERSIANI, B.R.; RODRIGUES, P.C.H. Geoprocessamento como ferramenta no estudo de correlação entre a dinâmica da cobertura vegetal e a evapotranspiração. Revista Brasileira de Recursos Hídricos, v.12, p.87-102, 2007. 
RIBEIRO, A.; FACCO, A.G.; SEDIYAMA, G.C.; SOUZA, M.J.H.; LEITE, F.P. Variación del almacenamiento de agua en el suelo en áreas de plantaciones forestales de crecimiento rápido entre diferentes fases de exposición y grados de inclinación del terreno. Mapping, n.99, p.52-60, 2005.

RODRIGUES, A.M.; PITA, G.P.A. Caracterização do escoamento e fluxo atmosférico de calor latente em Montado de Sobro. Silva Lusitana, v.11, p.165-184, 2003.

SOARES, J.V.; ALMEIDA, A.C. Modeling the water balance and soil water fluxes in a fast growing Eucalyptus plantation in Brazil. Journal of Hydrology, v.253, p.130-147, 2001.

SOUZA, A.P. de; ESCOBEDO, J.F.; DAL PAI, A.; GOMES, E.N. Estimativa da radiação global incidente em superfícies inclinadas por modelos isotrópicos e índice de claridade. Pesquisa Agropecuária Brasileira, v.45, p.339-350, 2010.
SVETLITCHNYI, A.A.; PLOTNITSKIY, S.V.; STEPOVAYA, O.Y. Spatial distribution of soil moisture content within catchments and its modelling on the basis of topographic data. Journal of Hydrology, v.277, p.50-60, 2003.

TURCO, J.E.P.; RIZZATTI, G.S. Avaliação de modelo matemático para estimar a radiação solar incidente sobre superfícies com diferentes exposições e declividades. Engenharia Agrícola, v.26, p.257-267, 2006.

TWINE, T.E.; KUSTAS, W.P.; NORMAN, J.M.; COOK, D.R.; HOUSER, P.R.; MEYERS, T.P.; PRUEGER, J.H.; STARKS, P.J.; WESELY, M.L. Correcting eddy-covariance flux underestimates over a grassland. Agricultural and Forest Meteorology, v.103, p.279-300, 2000.

VIANELLO, R.L.; ALVES, A.R. Meteorologia básica e aplicada. Viçosa: UFV, 2002. 449p.

Recebido em 31 de agosto de 2011 e aprovado em 8 de agosto de 2012 